\title{
CARACTERIZAÇÃO DE GEMAS FLORAIS DE PEREIRA (Pyrus sp.) RELACIONADA AO ABORTAMENTO FLORAL ${ }^{1}$
}

\author{
VALTAIR VERISSIMO ${ }^{2}$, FLAVIO GILBERTO HERTER ${ }^{3}$, ALEXANDRE COUTO RODRIGUES ${ }^{4}$, \\ JOÃO PETERSON GARDIN ${ }^{5}$, JOÃO BATISTA DA SILVA 6
}

\begin{abstract}
RESUMO - O objetivo do estudo foi avaliar o efeito do local, cultivar e época em parâmetros físicos, morfológicos e fisiológicos de gemas florais de pereira e o possível envolvimento com a ocorrência de abortamento de gemas florais no Sul do Brasil. Para isso, conduziram-se dois experimentos durante o ano de 2000. Foram coletadas gemas florais de três cultivares (cvs.), em três regiões no Sul do Brasil. Analisaram-se o volume, peso, comprimento e diâmetro de gema, peso seco de escamas, comprimento e peso seco da inflorescência, número de primórdios florais por gema e índice de necrose. Verificaram-se a ocorrência de duplicação de inflorescências e a formação de grande número de primórdios florais por gema nos locais onde os índices de abortamento foram maiores. As cvs. asiáticas apresentaram maior número de primórdios comparado à cv. Kieffer (híbrido). Na região de São Joaquim-SC, a pereira apresenta melhor adaptação, caracterizada por melhor formação da estrutura floral. As cvs. asiáticas, especialmente em Pelotas, apresentaram alterações em nível de primórdios florais, tais como: deformações, necrose de pistilo, abscisão, escurecimento de anteras e feixes vasculares. O comprimento da inflorescência permitiu diferenciar as cultivares, quanto à época de retomada do desenvolvimento floral final, sendo a cv. Kieffer mais precoce que as cvs. Nijisseiki e Housui.
\end{abstract}

Termos para indexação: Pyrus pyrifolia, Nijisseiki, Kieffer, morfologia, inflorescência, primórdio floral.

\section{CHARACTERIZATION OF PEAR FLOWER BUD (Pyrus sp.) AND THE RELATION WITH FLOWER BUD ABORTION}

\begin{abstract}
The objective of this study was to evaluate the effect of location, cultivar and time on the physical, morphological and physiological characteristics of pear flower bud, and possible envolvement with flower bud abortion, in the Southern of Brazil. Two experiments were conducted in the year 2000, in three locations and three cultivars. Volume, weight, length and bud diameter, dry weight of scales, inflorescence length, number of flower primordia per bud, inflorescence dry weight and internal necrosis degree of buds were evaluated. The occurrence of duplication of inflorescence and formation of a large number of flower primordia per buds in samples from locations with higher indexes of abortion were observed. Asian pear cultivars had larger number of flower primordia per bud than the cv. Kieffer (hybrid). In São Joaquim's area, the pear has a better adaptation, characterized by a better formation of the floral structure. The Asian pears, especially in Pelotas, also showed alterations in flower primordia, such as: deformations, abscission, pistil necrosis, darkening of anthers and vascular tissues. The length of the inflorescence allowed the differentiation of cultivars according to time of resumption of their final flower development, being the 'Kieffer' earlier than Nijisseiki and Housui cultivars.
\end{abstract}

Index terms: Pyrus pyrifolia, Nijisseiki, Kieffer, morphology, inflorescence, flower primordia.

\section{INTRODUÇÃO}

A cultura da pereira é uma alternativa para aumentar a eficiência e a diversificação do sistema produtivo, na região Sul do Brasil. Porém, existem fatores limitantes para a expansão da cultura, dentre os quais se destaca o abortamento de gemas florais, que, em alguns anos, dependendo da cultivar, varia de 30 a 100\% (Nakasu \& Leite, 1992).

Entre os fatores ecofisiológicos que podem ser a origem do problema, estão os relacionados ao clima (flutuações de temperatura e falta de frio), fatores nutricionais, com ênfase a carboidratos e micronutrientes, biologia floral e estresse hídrico. Até o momento, nenhuma hipótese foi comprovada como sendo o fator causal do distúrbio.

As gemas de flor e as inflorescências da pereira são similares às da macieira, sendo que, na pereira, contêm de sete a oito primórdios florais e são indeterminadas, enquanto as de macieira possuem cinco a seis primórdios e são determinadas (Westwood, 1978). A formação das gemas reprodutivas ocorre em três fases: a da indução; da diferenciação, que se caracteriza por modificações morfológicas, no período de verão e outono; e do desenvolvimento floral, o qual ocorre na primavera, após a superação da dormência. A iniciação floral ou diferenciação floral é a fase em que o meristema sofre uma série de modificações morfológicas que o transformam em flor ou inflorescência (Monet \& Bastard, 1970).

O trabalho teve por objetivo as caracterizações físicas, morfológicas e fisiológicas de gemas florais de diferentes cvs. de pereira, em diferentes condições climáticas no Sul do Brasil, visando a verificar possível envolvimento com o abortamento floral.

\section{MATERIALEMÉTODOS}

As avaliações foram realizadas em gemas de pereira de plantas adultas, enxertadas sobre Pyrus calleryana, coletadas no inverno de 2000, em três regiões diferentes no Sul do Brasil. Foram utilizadas as cultivares asiáticas Nijisseiki, que exige 900-1000 horas de frio (HF), e Housui, que exige cerca de $721 \mathrm{HF}$, e o híbrido Kieffer, com exigência de $300 \mathrm{HF}$. Em Pelotas, as amostras foram coletadas em plantas do pomar da Embrapa (224 m de altitude e coordenadas 52 $21^{\circ} \mathrm{W}$ e $31^{\circ} 52^{\prime \prime} \mathrm{S}$ ). Em Vacaria, as coletas foram no pomar da Embrapa Uva e Vinho $(960 \mathrm{~m}$, coordenadas $50^{\circ} 42^{\prime} \mathrm{W}$ e $28^{\circ} 33^{\prime} \mathrm{S}$ ). Em São Joaquim-SC, as coletas foram no pomar da Estação Exp. da EPAGRI (1.415 m, coordenadas 49 55' 56" W e $28^{\circ} 17^{\prime} 39^{\prime \prime} \mathrm{S}$ )

As regiões apresentam condições climáticas contrastantes: São Joaquim-SC, considerada de clima temperado, com cerca de $920 \mathrm{HF}$, como média anual; Pelotas-RS, apresenta variações bruscas de temperatura no inverno, com $550 \mathrm{HF}$; Vacaria-RS, classificada como intermediária, com cerca de 809 HF. Em cada uma destas regiões, o índice de abortamento floral final tem sido variável para uma mesma cultivar e ano.

Foram conduzidos dois experimentos, sendo o primeiro com objetivo de estudar o efeito do local, em três regiões, e, no segundo, o efeito da época de coleta para um mesmo local nas variáveis analisadas.

Experimento 1- Foram coletadas no fim do inverno, gemas florais das cvs. Nijisseiki e Housui, em três locais (São Joaquim, Vacaria

\footnotetext{
1 (Trabalho 148/2003). Recebido: 08/10/2003. Aceito para publicação: 29/04/2004. Apoio financeiro EMBRAPA, CNPq e JICA.

${ }^{2} \mathrm{Eng}^{\mathrm{o}} \mathrm{Agr}^{\circ}$. MSc., Fruticultura, FAEM/UFPEL, Pelotas-RS/ Brasil, E-mail: valtairverissimo@ yahoo.com.br.

${ }^{3}$ Eng $^{\circ}$ Agr $^{\circ}$. Dr., pesquisador EMBRAPA Clima Temperado, Pelotas-RS, E-mail: herter@ cpact.embrapa.br.

${ }^{4} \mathrm{Eng}^{\mathrm{O}} \mathrm{Agr}^{\circ}$. Dr., pesquisador CNPq RD, E-mail: rcale@ufpel.edu.br.

${ }^{5} \mathrm{Eng}^{\mathrm{O}} \mathrm{Agr}^{\circ}$., MSc., Fisiologia Vegetal, UFPEL.

${ }^{6} \mathrm{Eng}^{\mathrm{O}} \mathrm{Agr}^{\circ}$., Dr., livre docente, prof. Titular IMF-UFPEL, Pelotas-RS.
} 
TABELA 1 - Características físicas e morfológicas de gemas florais de cvs. de pereira em diferentes locais, durante o inverno de 2000.

\begin{tabular}{|c|c|c|c|c|c|c|}
\hline \multirow[t]{2}{*}{ Parâmetro \Local } & \multicolumn{3}{|c|}{ cv. Nijisseiki } & \multicolumn{3}{|c|}{ cv. Housui } \\
\hline & S. Joaquim & Vacaria & Pelotas & S. Joaquim & Vacaria & Pelotas \\
\hline Diâmetro de gema $(\mathrm{mm})$ & $6,08 \mathrm{~b}$ & $6,01 \mathrm{~b}$ & $6,54 \mathrm{a}$ & $5,63 \mathrm{c}$ & $6,35 \mathrm{a}$ & $6,00 \mathrm{~b}$ \\
\hline Comprimento de gema (mm) & $11,50 \mathrm{a}$ & $11,45 \mathrm{a}$ & $11,16 \mathrm{a}$ & $13,62 \mathrm{a}$ & $12,79 \mathrm{~b}$ & $13,14 \mathrm{ab}$ \\
\hline Peso túrgido de gema $(\mathrm{g})^{*}$ & $0,27 \mathrm{a}$ & $0,24 \mathrm{a}$ & $0,27 \mathrm{a}$ & $0,28 \mathrm{ab}$ & $0,31 \mathrm{a}$ & $0,28 \mathrm{~b}$ \\
\hline Peso seco escamas $(\mathrm{g})^{*}$ & $1,07 \mathrm{a}$ & $0,98 \mathrm{~b}$ & $1,08 \mathrm{a}$ & $0,87 \mathrm{~b}$ & $0,86 \mathrm{~b}$ & $0,90 \mathrm{a}$ \\
\hline Peso seco inflorescência $(\mathrm{g})^{*}$ & $0,21 \mathrm{~b}$ & $0,19 \mathrm{c}$ & $0,27 \mathrm{a}$ & $0,23 \mathrm{c}$ & $0,27 \mathrm{a}$ & $0,24 \mathrm{~b}$ \\
\hline Peso seco total $(\mathrm{g})^{*}$ & $1,28 \mathrm{~b}$ & $1,18 \mathrm{c}$ & $1,35 \mathrm{a}$ & $1,10 \mathrm{~b}$ & $1,12 \mathrm{ab}$ & $1,15 \mathrm{a}$ \\
\hline Comp. inflorescência (mm) & $6,09 \mathrm{~b}$ & $6,58 \mathrm{a}$ & $6,74 \mathrm{a}$ & $6,03 \mathrm{a}$ & 5,99 a & $5,12 \mathrm{~b}$ \\
\hline Volume das gemas $\left(\mathrm{cm}^{3}\right)^{*}$ & $5,88 \mathrm{a}$ & $5,20 \mathrm{~b}$ & $6,02 \mathrm{a}$ & $6,24 \mathrm{~b}$ & $6,51 \mathrm{a}$ & $6,12 \mathrm{~b}$ \\
\hline $\mathrm{N}^{\mathrm{o}}$ primórdios florais & $11,44 \mathrm{~b}$ & $9,56 \mathrm{c}$ & $15,81 \mathrm{a}$ & $11,98 \mathrm{~b}$ & $14,26 \mathrm{a}$ & $15,69 \mathrm{a}$ \\
\hline
\end{tabular}

Médias seguidas pela mesma letra, na linha da cv., não diferem pelo Teste Duncan a 5\%. * Dados médios de conjuntos de 15 gemas florais.

e Pelotas), nas quais foram analisadas as seguintes variáveis: peso túrgido, comprimento, diâmetro, peso seco e volume das gemas, peso seco de escamas (brácteas), comprimento e peso seco de inflorescência, número de primórdios florais e índice de necrose das gemas. O delineamento experimental utilizado foi um fatorial $3 \times 2$, sendo três locais e duas cultivares, inteiramente casualizado, com 9 repetições de 15 gemas para cada tratamento. Foram realizadas análises individuais para cada local. Após, foi feito teste de homogeneidade das variâncias e, posteriormente, realizada análise conjunta dos dados. Foi feita análise de variação, e a comparação de médias pelo teste Duncan $(\mathrm{p}=0,05)$. Foram determinadas as intensidades de ocorrência de abortamento floral para cada cultivar e local.

Experimento 2 - O experimento foi conduzido em Pelotas-RS, nas cvs. Nijisseiki, Housui e Kieffer. As gemas florais foram coletadas em seis épocas diferentes (de agosto a início de setembro de 2000). Foram analisadas as mesmas variáveis do experimento anterior. O experimento foi um fatorial $3 \times 6$, sendo os fatores Cultivar (Nijisseiki, Housui e Kieffer) e Épocas (E1=03-08; E2=11-08; E3=17-08; E4=24-08; E5=31-08 e E6=08-09), inteiramente casualizado, com 4 repetições de 10 gemas para cada tratamento. Foi feita a análise de variação, e a comparação de médias pelo teste Duncan $(\mathrm{p}=0,05)$. Foram determinadas as intensidades de ocorrência de abortamento floral para cada cultivar e época de coleta.

\section{RESULTADOS E DISCUSSÃO}

Com base na análise estatística, foi possível verificar a ocorrência de variação nos parâmetros analisados, entre os diferentes locais estudados, bem como entre as diferentes épocas de coletas das gemas florais

Em resultados relativos à comparação entre locais, verificou-se que em Pelotas o número de primórdios florais foi alto (aproximadamente 16/ por gema) nas cvs. Housui e Nijisseiki, diferindo da região de São Joaquim, que teve menor número de primórdios. Em Vacaria, na 'Nijisseiki', o número de primórdios foi ainda menor comparado a São Joaquim (Tab. 1).

A cv. 'Nijisseiki' em Pelotas apresentou maiores valores em quase todos os parâmetros analisados. Em São Joaquim, esta mesma cultivar apresentou menor peso seco de inflorescências e menor peso seco total, comparado a Pelotas, além de número de primórdios menor. A região de Vacaria diferiu ainda de São Joaquim, apresentando menor peso seco de escamas, volume de gemas, peso seco de inflorescência, peso seco de escamas e peso seco total. Parte dessa diferença, possivelmente, seja devida ao menor número de primórdios. Por outro lado, apresentou maior comprimento das inflorescências (Tab. 1).

Em Pelotas, na 'Housui', houve maior número de primórdio, maior peso seco de escamas e peso seco total das gemas. Contrariamente, em São Joaquim, ocorreu menor número de primórdios, menor diâmetro das gemas, peso seco de inflorescências e peso seco total (Tab.1).

Resultados similares foram obtidos por Verissimo et al. (2002), no qual foi verificado, em 1999, em Pelotas, um grande número de primórdios florais por gema, e os índices de abortamento floral foram superiores a 90\%. Em São Joaquim, os autores observaram menores índices de abortamento e melhores parâmetros de qualidade de gemas. Quanto aos índices de necrose em função do local, com base nas análises de gemas em laboratório, verificou-se que na cv. Housui, em Pelotas, ocorreram os maiores índices de necrose, seguido por São Joaquim e Vacaria. Para a 'Nijisseiki', os maiores índices de necrose ocorreram em Vacaria, seguido por São Joaquim, e os menores em Pelotas (Fig. 1). Há que considerar que os danos de necroses em São Joaquim, provavelmente, sejam ainda menores, pois a endodormência se completa mais cedo que as outras duas regiões. Em Pelotas, a 'Nijisseiki' apresentou a maior parte dos primórdios sadios até agosto. Sabe-se que as necroses podem ser observadas ainda no outono. Porém, de acordo com GARDIN (2002), nesta cultivar, o abortamento intensifica-se na fase que antecede a floração.

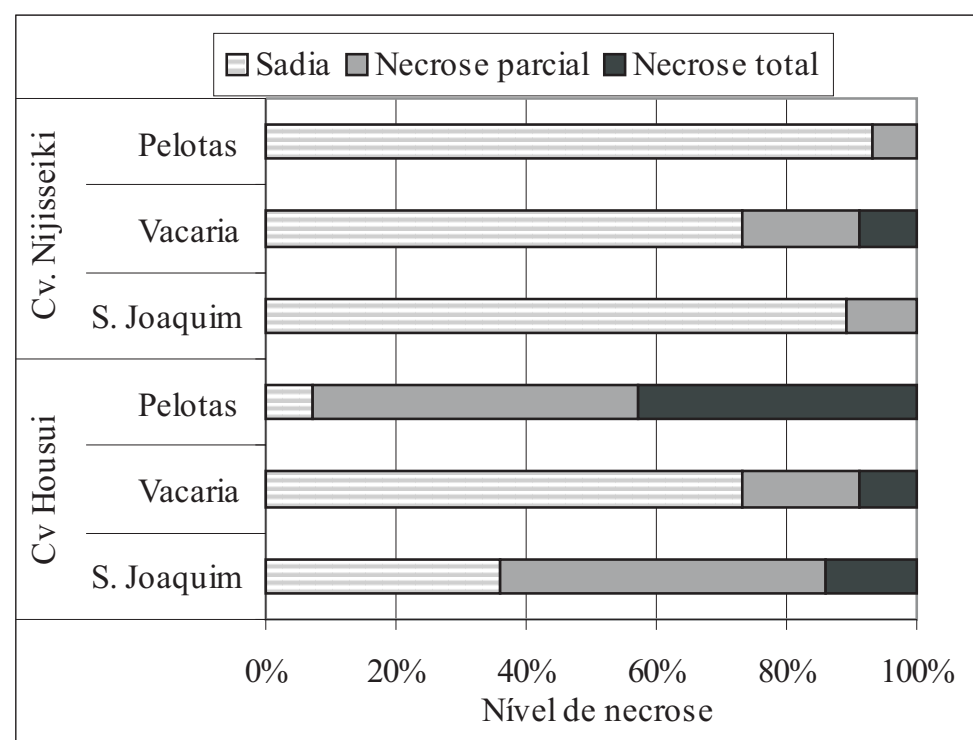

FIGURA 1 - Percentagem de necrose parcial ou total dos primórdios em gemas florais das cvs. Housui e Nijisseiki, em três locais do Sul do Brasil, no início de setembro de 2000.

Quanto aos índices de necrose em função da época, nas três primeiras coletas, verificou-se que a 'Nijisseiki' apresentou gemas florais sadias (Fig. 2). A partir da quarta época de avaliação (24-08), começaram a aparecer gemas com necrose parcial. Nas últimas coletas (31-08 e 08-09), o problema se intensificou, sendo que nas inflorescências duplicadas muitas apresentavam apenas um lado necrosado (Fig. 3a e 3b). Já em 'Housui', na primeira coleta, foram observadas muitas gemas com necrose parcial e inclusive necrose severa (Fig. 2), enquanto na 'Kieffer', a necrose ocorreu a partir da terceira coleta (17-08), mas em poucas gemas.

Esses resultados levam a crer que há maior gasto de energia na formação das gemas e de maior número de primórdios, o que pode estar levando ao esgotamento das reservas nutricionais das plantas. $\mathrm{Na} \mathrm{cv}$. Nijisseiki, o número máximo de primórdios observados ocorreu em PelotasRS (região com menor acúmulo de horas de frio), com até 31 primórdios florais por gema, e não raro a ocorrência de 20 ou mais primórdios por gema. O esperado seria entre 7 e 8 primórdios florais por gema. 


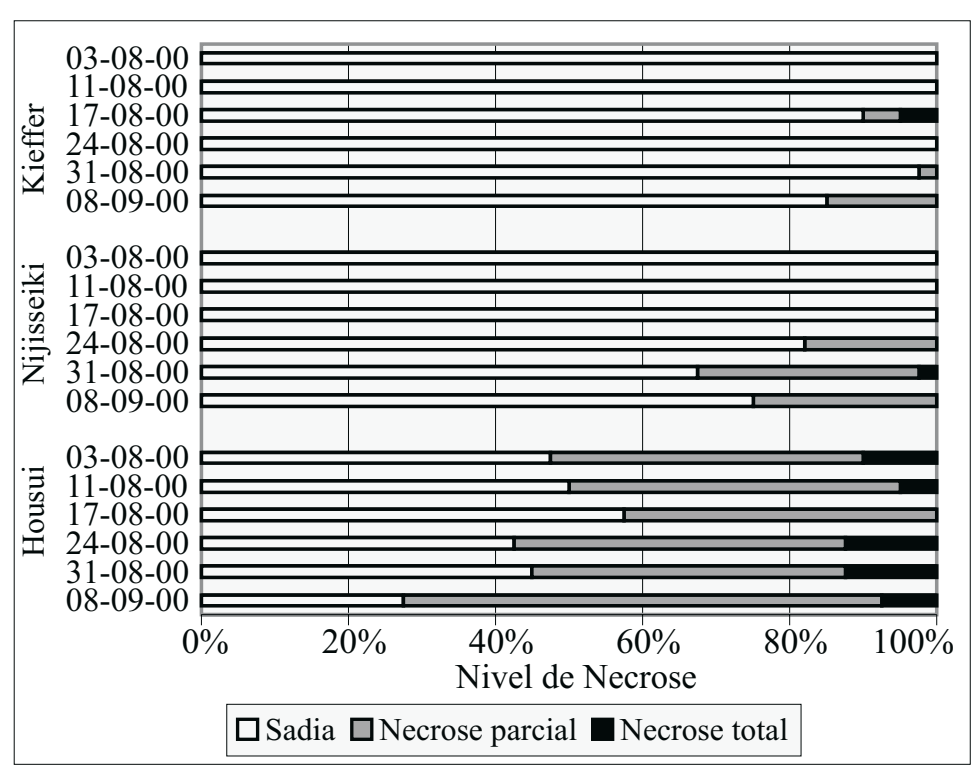

FIGURA 2 - Percentagem de necrose parcial ou total de primórdios em gemas florais de pereira, cvs. Housui, Nijisseiki e Kieffer, observadas em seis épocas, de 03/08 a 08/09/2000, em Pelotas-RS.

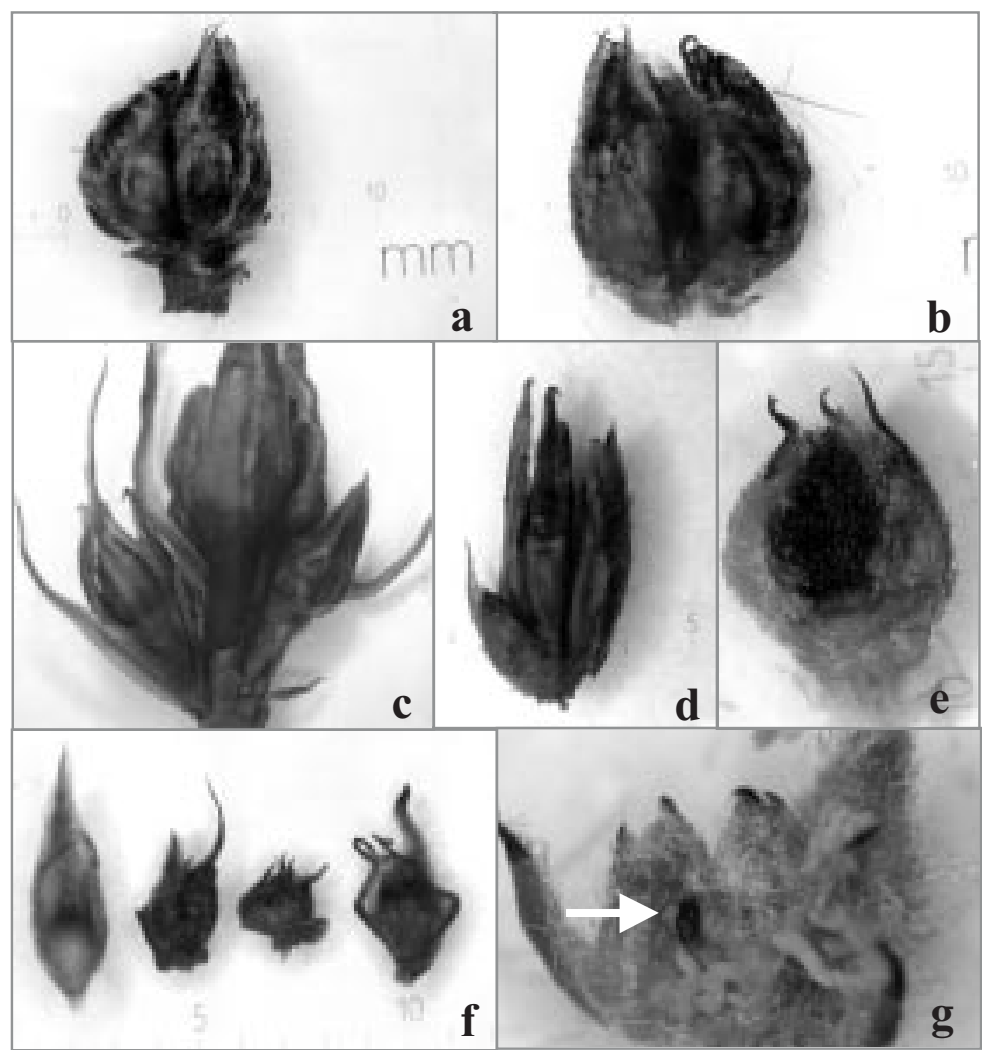

FIGURA 3 - a) Inflorescência da cv. Nijisseiki em 08-09-2000, com duplicação.6X; b) Inflorescência com duplicação (cv. Nijisseiki). 8X; c) Conjunto de primórdios florais sadios da 'Kieffer' (08-09-2000)6X; d) Conjunto de primórdios florais débeis 'Kieffer' (03-08-2000)8X; e) Primórdio floral da cv. Nijisseiki com abscisão.20X; f) Primórdio floral normal (esquerda) e os outros com deformações (cv. Nijisseiki).10X; g) Primórdio floral da cv. Nijisseiki com sintoma de necrose de estigma. 25X.

Nesse estudo, como foi visto, verificou-se um grande número de primórdios florais por gema, especialmente nas cvs. asiáticas, fato acompanhado pela ocorrência de duplicação ou bifurcação de inflorescências, e mais freqüente nas regiões de Pelotas e Vacaria. Isto coincidiu também com índices de abortamento a campo bastante elevados em Pelotas. Entretanto, em São Joaquim, as inflorescências tiveram menor número de primórdios, e índices menores de abortamento, possivelmente influenciado por condições climáticas mais adequadas desde a indução à diferenciação floral, pois, nesta região, as temperaturas máximas médias foram inferiores em comparação aos dois outros locais (Fig. 4).

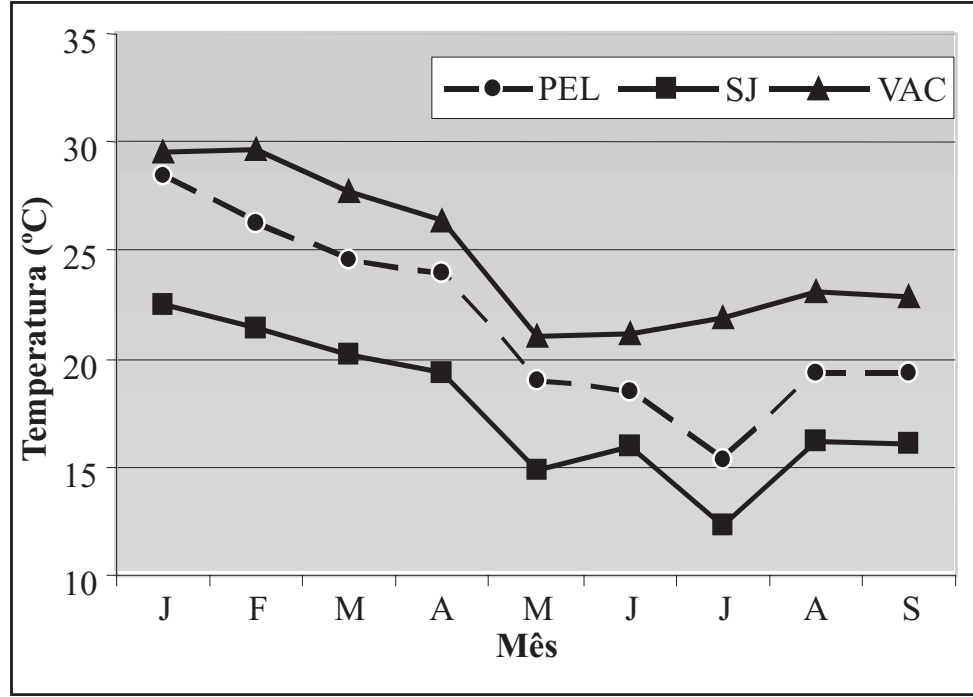

FIGURA 4 - Temperatura máxima média $\left({ }^{\circ} \mathrm{C}\right)$ observada em Pelotas, Vacaria e São Joaquim, de janeiro a setembro de 2000. Embrapa Clima Temperado, Pelotas-RS, 2000

A duplicação da inflorescência e o grande número de primórdios, como tem sido verificado, podem ser uma resposta da planta às altas temperaturas durante o verão e o outono, ou às freqüentes oscilações de temperatura durante o período de dormência, principalmente nas regiões de Pelotas e Vacaria. Selli et al. (1985) atribuíram as causas de abortamento em pessegueiros e nectarineiras, na Itália, à condição climática, principalmente pelas elevadas temperaturas no outono seguidas de abrupta redução.

Aparentemente, o frio exerce função importante na ocorrência de abortamento em pereira, mesmo que não seja o principal fator causal. $\mathrm{O}$ frio pode ter ação indireta, isto porque sua ocorrência afeta o metabolismo da planta. O maior número de primórdios formados também pode ser decorrente da qualidade de frio, pois, em São Joaquim, além de haver maior acúmulo de frio, o mesmo inicia-se mais cedo e com maior intensidade (Tab. 2), possibilitando a suficiente redução do metabolismo e crescimento. $\mathrm{O}$ mesmo não ocorre em Pelotas, onde, além de haver menor acúmulo de frio, o seu início é mais tardio e gradual, não havendo, assim, a suficiente redução no metabolismo das plantas a fim de possibilitar uma dormência satisfatória.

TABELA 2 - Número de Horas de Frio $\left(\leq 7,2^{\circ} \mathrm{C}\right)$ observado em São Joaquim, Vacaria e Pelotas, nos meses de maio a setembro, para o ano de 2000. Embrapa Clima Temperado, PelotasRS, 2000.

\begin{tabular}{lcccccc}
\hline Local/Mês & M & J & J & A & S & Soma \\
\hline S. Joaquim & 227 & 212 & 240 & 177 & 149 & 1005 \\
Vacaria & 176 & 170 & 156 & 174 & 86 & 762 \\
Pelotas & 79 & 105 & 120 & 133 & 48 & 485 \\
\hline
\end{tabular}

Em damasqueiros, a necrose de gemas florais é mais freqüente em invernos com diferentes acúmulos de frio e em distintos estádios fenológicos. Além da queda de gemas, que é mais freqüente antes do florescimento, há ocorrência de flores com anomalias, sendo que os danos foram atribuídos às condições climáticas do inverno, que não possibilitaram o suficiente acúmulo de frio e a adequada formação das gemas florais (Guerriero et al., 1985). Segundo estes autores, uma hipótese seria que o início de inverno ameno não permite a acumulação de frio suficiente, e promove um crescimento lento em todas as gemas, e, em geral, as plantas em dormência não suportam 
TABELA 3 - Características físicas e morfológicas de gemas florais, de três cultivares em seis épocas, em Pelotas-RS. 2000.

\begin{tabular}{|c|c|c|c|c|c|c|c|c|}
\hline Parâmetros & & Nijisseiki & Housui & Kieffer & Parâmetros & Nijisseiki & Housui & Kieffer \\
\hline Comprimento & E 1 & $12,00 \mathrm{a}$ & $13,68 \mathrm{a}$ & $15,63 \mathrm{ab}$ & Comprimento de & $5,32 \mathrm{c}$ & $5,63 \mathrm{~b}$ & $4,84 \mathrm{c}$ \\
\hline \multirow{6}{*}{ de Gemas (mm) } & E 2 & $11,21 \mathrm{a}$ & $13,91 \mathrm{a}$ & $14,60 \mathrm{~cd}$ & Inflorescência & $5,59 \mathrm{bc}$ & $5,20 \mathrm{c}$ & $4,85 \mathrm{c}$ \\
\hline & E 3 & $11,58 \mathrm{a}$ & $14,16 \mathrm{a}$ & $14,76 \mathrm{~cd}$ & $(\mathrm{~mm})$ & $5,37 \mathrm{c}$ & $4,99 \mathrm{c}$ & $4,50 \mathrm{c}$ \\
\hline & E 4 & $11,23 \mathrm{a}$ & $13,97 \mathrm{a}$ & $15,21 \mathrm{bc}$ & & $6,41 \mathrm{a}$ & $6,36 \mathrm{a}$ & $5,48 \mathrm{~b}$ \\
\hline & E 5 & $11,68 \mathrm{a}$ & $14,04 \mathrm{a}$ & $16,03 \mathrm{a}$ & & $5,90 \mathrm{~b}$ & $5,84 \mathrm{~b}$ & $5,69 \mathrm{~b}$ \\
\hline & E 6 & $11,44 \mathrm{a}$ & $13,83 \mathrm{a}$ & $14,38 \mathrm{~d}$ & & $5,90 \mathrm{~b}$ & $5,56 \mathrm{~b}$ & 7,86 a \\
\hline & Media & $11,53 \mathrm{C}$ & $13,93 B$ & $15,10 \mathrm{~A}$ & & $5,75 \mathrm{~A}$ & 5,59 B & 5,54 B \\
\hline Peso Seco da & E 1 & $0,18 \mathrm{ab}$ & $0,16 \mathrm{ab}$ & $0,09 \mathrm{~b}$ & $\mathrm{~N}^{\mathrm{o}}$ de Primórdios & $18,19 \mathrm{ab}$ & $16,48 \mathrm{~b}$ & $8,34 \mathrm{a}$ \\
\hline Inflorescência & E 2 & $0,20 \mathrm{a}$ & $0,16 \mathrm{ab}$ & $0,08 \mathrm{bc}$ & Florais por gema & $20,36 \mathrm{a}$ & $17,41 \mathrm{ab}$ & $7,42 \mathrm{a}$ \\
\hline \multirow[t]{5}{*}{$(\mathrm{g}) *$} & E 3 & $0,16 \mathrm{~b}$ & $0,15 \mathrm{bc}$ & $0,08 \mathrm{bc}$ & & $15,81 \mathrm{c}$ & $17,06 \mathrm{ab}$ & $8,27 \mathrm{a}$ \\
\hline & E 4 & $0,17 \mathrm{ab}$ & $0,13 \mathrm{bc}$ & $0,05 \mathrm{c}$ & & $16,25 \mathrm{bc}$ & $15,29 \mathrm{~b}$ & $8,20 \mathrm{a}$ \\
\hline & E 5 & $0,20 \mathrm{a}$ & $0,19 \mathrm{a}$ & $0,15 \mathrm{a}$ & & $16,84 \mathrm{bc}$ & $19,20 \mathrm{a}$ & $8,18 \mathrm{a}$ \\
\hline & E 6 & $0,20 \mathrm{a}$ & $0,12 \mathrm{c}$ & $0,09 \mathrm{~b}$ & & $17,63 \mathrm{bc}$ & $16,37 \mathrm{~b}$ & 7,91 a \\
\hline & Média & $0,185 \mathrm{~A}$ & 0,152 B & $0,092 \mathrm{C}$ & & $17,5 \mathrm{~A}$ & $17,0 \mathrm{~A}$ & 8,1 B \\
\hline
\end{tabular}

Médias seguidas pela mesma letra minúscula na coluna, maiúscula na linha, não diferem pelo Teste Duncan a 5\%.* Dados de 10 gemas.

este crescimento.

A dinâmica de carboidratos, segundo Gardin (2002), em Pelotas, é diferente da verificada em São Joaquim, pois ocorre uma diminuição do amido, sem, entretanto, aumentar os sólidos solúveis, no inverno. Isso se deve à manutenção de altas taxas respiratórias. Este fato pôde ser confirmado por Verissimo (2002), quando encontrou altos níveis de boro nas gemas, durante o inverno, em Pelotas, o que é um indício de que as plantas não reduzem suficientemente seu metabolismo. Segundo Faust (1989), altos níveis deste microelemento estão associados ao aumento da taxa respiratória.

No experimento referente a épocas de coletas, verificou-se que, na 'Kieffer', houve gradual aumento no comprimento das gemas e das inflorescências (Tab. 3). A medida do comprimento das inflorescências permitiu diferenciar as cultivares, quanto à época de retomada do desenvolvimento floral final, sendo o híbrido 'Kieffer' mais precoce comparado às cvs. Nijisseiki e Housui. Observou-se não ocorrer variação quanto ao número de primórdios entre as diferentes épocas em todas as cultivares.

Entre cultivares, observou-se que o número de primórdios florais por gema foi maior nas 'Nijisseiki' e 'Housui' comparado à cv. Kieffer. Quanto ao comprimento das gemas, a 'Kieffer' apresentou os maiores valores, mas, por outro lado, teve menor peso seco de inflorescência. As gemas dessa cultivar geralmente são mais compridas e afiladas que as gemas da 'Nijisseiki' e 'Housui'. O peso seco das inflorescências nas cvs. asiáticas foi maior que na 'Kieffer', provavelmente em função do maior número de primórdios (Tab. 3).

$\mathrm{Na}$ cv. Kieffer, ocorre, provavelmente, devido à melhor distribuição das reservas nutricionais pela formação de menor número de primórdios florais por gema, conduzindo a um menor índice de abortamento, como pode ser observado nos resultados, onde os primórdios são mais vigorosos (Fig. 3c). Raramente, observou-se na 'Kieffer' a duplicação da inflorescência, pouco desenvolvida, debilitada e com sinais de necrose (Fig. 3d).

Durante as análises das gemas, foram observadas, mais freqüentemente em Pelotas, principalmente nas cvs. asiáticas, a ocorrência de algumas alterações em nível de primórdios florais, como abscisão (Fig. 3e), deformações (Fig. 3f), necrose de pistilo (Fig. 3g) e escurecimento de anteras e feixes vasculares. Este resultado indica que esta região pode ser considerada marginal para o cultivo de cultivares de pereira com alta exigência em frio.

A formação de zona de abscisão na base dos primórdios florais é um indício de que algum tipo de estresse esteja envolvido. Possivelmente, seja por esse mecanismo que as gemas abortadas se desprendem quando tocadas. Segundo Taiz \& Zieger (1991), os níveis endógenos de etileno aumentam em condições de estresse ambiental e abscisão.

Em relação à necrose de pistilo nas gemas, sintoma semelhante foi descrito em pessegueiro por Crossa-Raynaud et al. (1985), bem como outras anomalias em flores. A malformação é diferente da necrose e pode ser originada ainda no outono, e estar relacionada à fase de diferenciação floral, enquanto a necrose pode ser em função de competição por reservas nutricionais. Estes sintomas podem ser causados por inverno ameno ou por altas temperaturas na fase que antecede o fim da dormência.

\section{CONCLUSÕES}

1. O aumento no número de primórdios florais por gema é decorrente da duplicação da inflorescência e contribui para os altos índices de abortamento de gemas florais, nas cvs. Nijisseiki e Housui, principalmente na região de Pelotas.

2. O maior número de primórdios florais por gema ocorre com maior freqüência nas cultivares asiáticas, sendo acompanhados de deformações, necrose de pistilo, abscisão, escurecimento de anteras e feixes vasculares.

3. Nas regiões como em São Joaquim, em Santa Catarina, onde a pereira apresenta melhor adaptação, verifica-se melhor formação da estrutura floral.

4. O comprimento das inflorescências permitiu diferenciar as cultivares quanto à época de retomada do desenvolvimento floral final, sendo o híbrido 'Kieffer' mais precoce comparado às cvs. Nijisseiki e Housui.

\section{REFERÊNCIAS BIBLIOGRÁGICAS}

CROSSA-RAYNAUD, P.; SOLEILLE, B.; MARTINEZ-TELLEZ, J.; IRAIDI, B. Peach flower sterility and its consequences on produtivity. Acta Horticulturae, Wazenigen, 173, p.93-102, 1985.

FAUST, M. Physiology of temperate zone fruit tress. New York: J. Wiley, 1989.338p.

GARDIN, J. P. P. Abortamento de gemas florais e níveis de carboidratos em gemas e ramos de pereira, cultivar Nijisseiki, no outono e inverno. 2002. 40f. Dissertação (Mestrado em Fisiologia Vegetal) - IB-Universidade Federal de Pelotas, PelotasRS, 2002.

GUERRIERO, R.; VITI, R.; BARTOLINI, S. Winter changes in the appearance of flower cup anomalies in a italian late blooming variety. Acta Horticulturae, Wageningen, n.192, p.49-56, 1985.

MONET, R.; BASTARD, Y. Les mécanismes de floraison chez Ia pecher. Bulletin Techenique Informative, Paris, v.248, p.173-176, 1970.

NAKASU, B. H.; LEITE, D. L. Pirus 9 - seleção de pereira para o Sul do Brasil. Horti-sul, Pelotas, v.2, n.3, p.19-20, 1992.

SELLI, R.; MONTALDI, P.; BAIESE, G. Cascolla delle gemmea fiore 
su pesche, nectarine e percoche. Rivista di Frutticoltura, Bologna, n. 8, p.43-49, 1985.

TAIZ, L.; ZIEGER, E. Plant physiology. Redwood City, California: The Benjamin/Cumming Publishing, 1991. 559p.

VERISSIMO, V.; GARDIN, J. P.; TREVISAN, R.; SILVA, J. B.; HERTER, F. G. Morphological and physical parameters of flower buds of trees of two japanese pear cultivars grown at three different areas of southern Brazil, and their relationship with flower bud abortion intensity. Acta Horticulturae, Wageningen, n.587, p.381-387, 2002. VERISSIMO, V. Caracterização de parâmetros físicos, químicos e morfológicos de gemas florais de pereira no Sul do Brasil, e sua relação com o abortamento. 2002. 58f. Tese (Mestrado) Universidade Federal de Pelotas, Pelotas-RS, 2002.

WESTWOOD, M. N. Temperate-zone pomology. San Francisco: W. H. Freemen, 1978. 428p. 